\title{
Scanning electron microscopy of the collodion membrane from a self-healing collodion baby*
}

\author{
Hiram Larangeira de Almeida Jr. ${ }^{1,2}$ \\ Isabelle Maffei Guarenti² \\ Luis Antônio Suita de Castro ${ }^{3}$
}

\author{
Henrique Isaacsson ${ }^{1,2}$ \\ Ricardo Marques e Silva ${ }^{1}$
}

DOI: http://dx.doi.org/10.1590/abd1806-4841.20153732

\begin{abstract}
Self-healing collodion baby is a well-established subtype of this condition. We examined a male newborn, who was covered by a collodion membrane. The shed membrane was examined with scanning electron microscopy. The outer surface showed a very compact keratin without the normal elimination of corneocytes. The lateral view of the specimen revealed a very thick, horny layer. The inner surface showed the structure of lower corneocytes with polygonal contour. With higher magnifications villous projections were seen in the cell membrane.
\end{abstract}

Keywords: Ichthyosis; Keratinocytes; Microscopy, electron, scanning

\section{INIRODUCTION}

The term Collodion Baby, coined by Hallopeu in 1884 , is not a specific disease, it describes a transient appereance at birth and neonatal life. ${ }^{1}$

Affected children are covered by a taut, cellophane-like transparent membrane which is perforated by the lanugo and scalp hair. This condition can partially impair some vital functions in the first days of life, such as suction and breathing. ${ }^{2,3}$ It is very rare, with an estimated incidence rate of 0.11 per million inhabitants according to a large French survey. ${ }^{4}$

This membrane with variable flexibility may lead to ectropion, eclabion and distortion of the nose and ears. ${ }^{5}$ Finger tips are often tapered and hands are held in partial flexion.

The membrane wrinkles cause fluid loss and termoregulation abnormalities, therefore increasing the risk of infection. 5,6 These newborns should be monitored carefully in intensive care units and receive appropriate and supportive treatment, as morbidity and mortality rates are high. ${ }^{4-6}$

Usually, this membrane is peeled off within two weeks but it can take several weeks to shed completely.
Most collodion babies later develop one of the several types of autosomal recessive congenital ichthyoses (ARCI), such as lamellar ichthyosis (LI) or congenital ichthyosiform erythroderma. ${ }^{6}$

Self-healing or self-improving collodion baby is a well-established subset of this condition. ${ }^{5}$ Typically, the membrane is eliminated with minimal residual desquamation; $10-24 \%$ of collodion babies are selfhealing ${ }^{6}$. The molecular defect is already known and patients have mutations in the TGM1 gene, which regulates the expression of transglutaminase 1 , an enzyme involved in epidermal differentiation. ${ }^{7,8}$

We could not find any report of scanning electron microscopy (SEM) of the collodion membrane in the literature.

\section{METHODS}

We examined a male newborn, who was covered by a collodoin membrane (Figure 1). Fissures were observed in the trunk; we also noticed a light ectropion and eclabion. After elimination of the membrane, the skin assumed a normal appearance. The case was classified as self-improving collodion baby.

Received on 29.05.2014.

Approved by the Advisory Board and accepted for publication on 15.07.2014.

Work performed at the Laboratório de Microscopia Eletrônica - Universidade Federal de Pelotas (UFPel); Empresa Brasileira de Pesquisa Agropecuária Clima Temperado (EMBRAPA CPA-CT) Pelotas; Programa de Pós-graduação em Saúde e Comportamento Universidade Católica de Pelotas (UCPel) - Pelotas (RS), Brazil. 


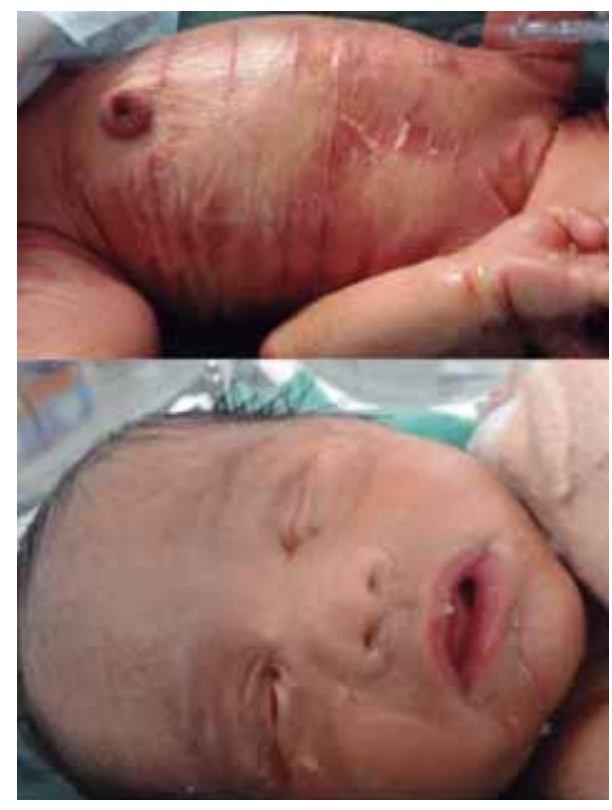

FiguRE 1:

Clinical

aspects with

covering

membrane

on the trunk

and face, with

light

ectropion and

no eclabium.

The shed membrane was routinely processed for scanning electron microscopy, in order to examine its three-dimensional ultrastructural aspects.

\section{RESULTS}

The inner and the outer surfaces of the collodion membrane were examined, since it was also placed inverted in the stub for ultrastructural examination..

The outer surface showed a compact keratin and perforation by vellus hairs (Figures $2 \mathrm{~A}$ and $2 \mathrm{~B}$ ). With higher magnification, this compactness became more evident, while the normal elimination of corneocytes was not observed (Figure 2C). The physiologic elimination of corneocytes, also known as desquamatio insensibilis, can easily be seen on the surface of normal skin for comparison (Figure 2D).

Examination of the lateral view of the specimen showed a very thick, horny layer, which did not reveal the normal basket weave aspect that is observed with SEM (Figure 3).

At a magnification of $x 700$, examination of the inner surface showed what is probably the structure of lower corneocytes, which have a polygonal contour (Figure 4).

With higher magnifications $(\times 2.700-4.000)$ villous projections could be seen in the cell membrane, as well as the irregular cell outline and some intercellular clefts (Figure 5).

\section{DISCUSSION}

Our results help to describe the threedimensional aspects of the collodion membrane, which is formed by multiple layers of corneocytes
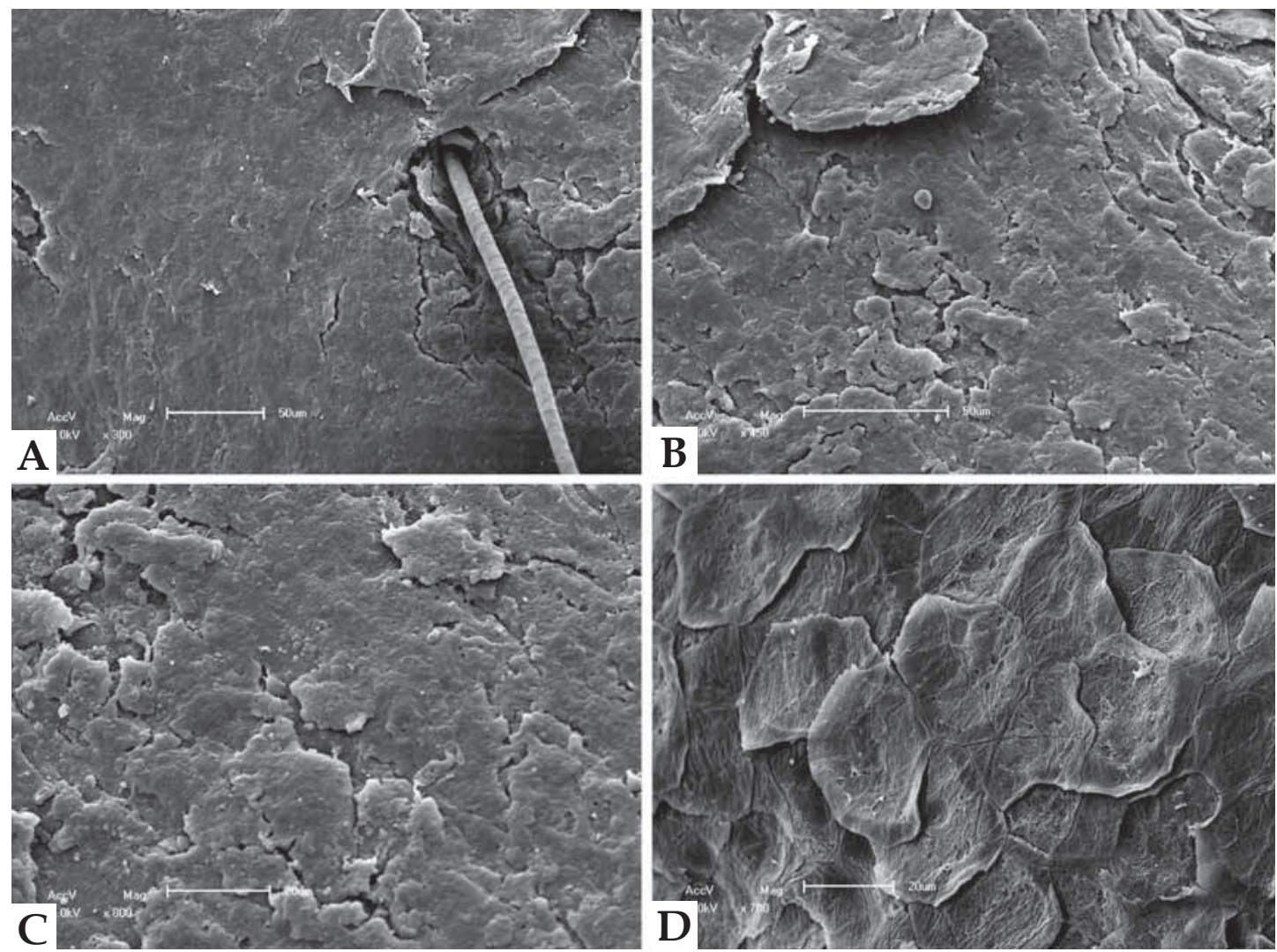

Figure 2:

Scanning electron microscopy of outer surface- a. compact membrane with a perforating vellous hair (x300). b. compact membrane without released corneocytes (x450). c. detail of the membrane with stony aspect (x800). $\mathbf{d}$. comparison with normal control releasing corneocytes (x700). 


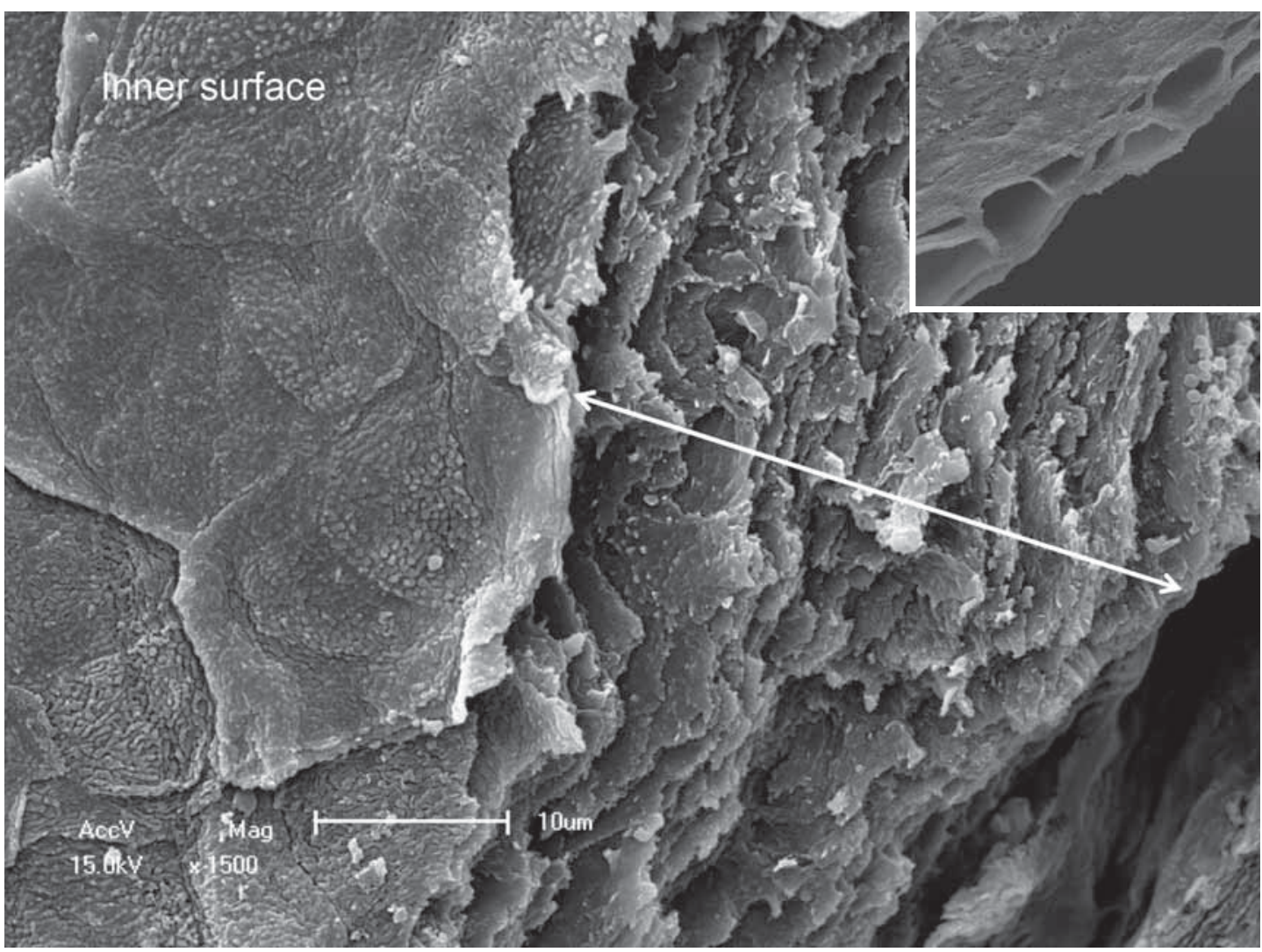

FIGURE 3: Scanning electron microscopy - lateral view of the collodion membrane showing multilayered corneocytes (x1.500). Inset with normal skin showing the "basket weave "aspect of the horny layer (x1.200).

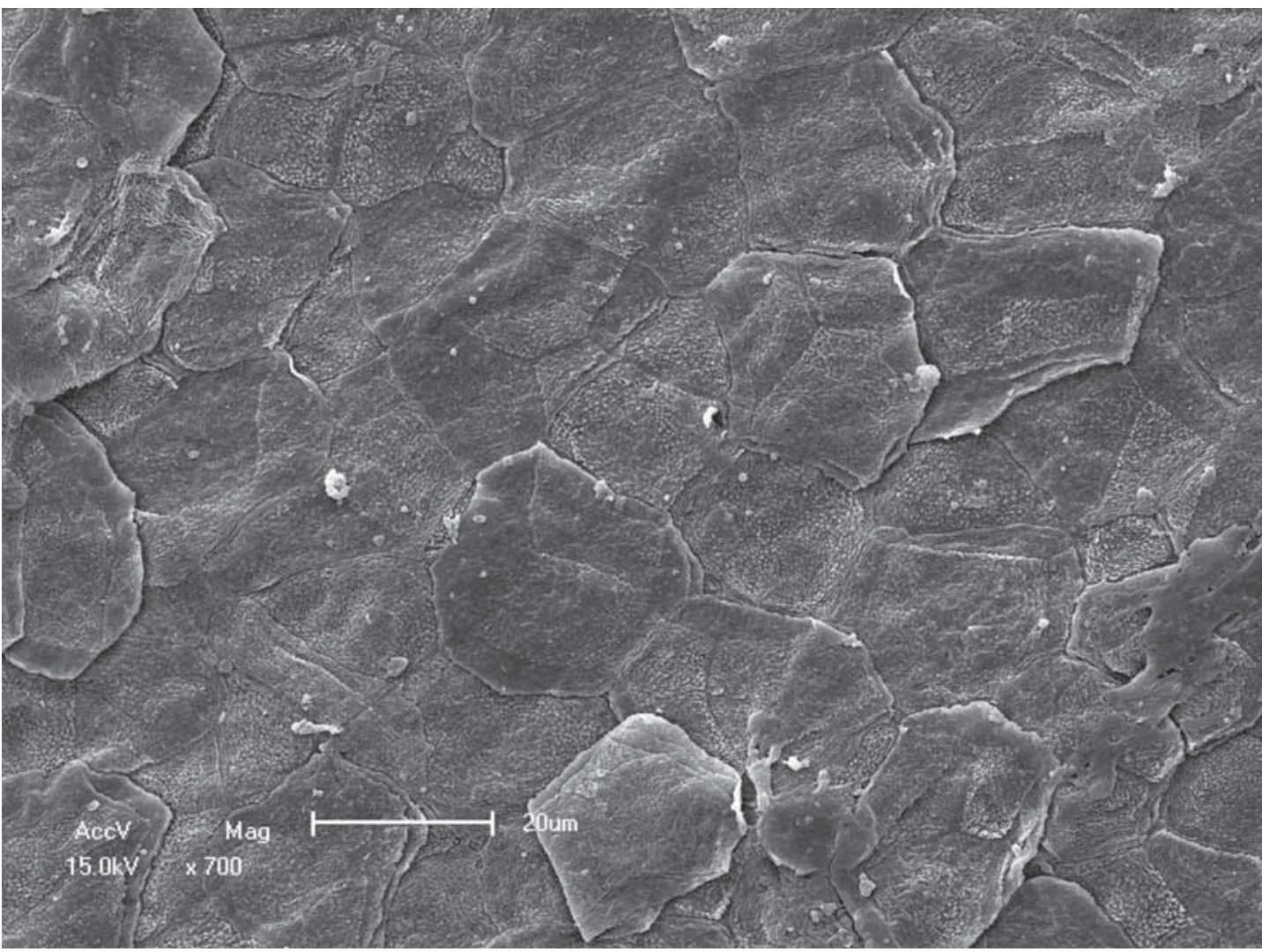

Figure 4:

Scanning electron microscopy - general view of the inner surface showing irregular lower corneocytes $(x 700)$. 

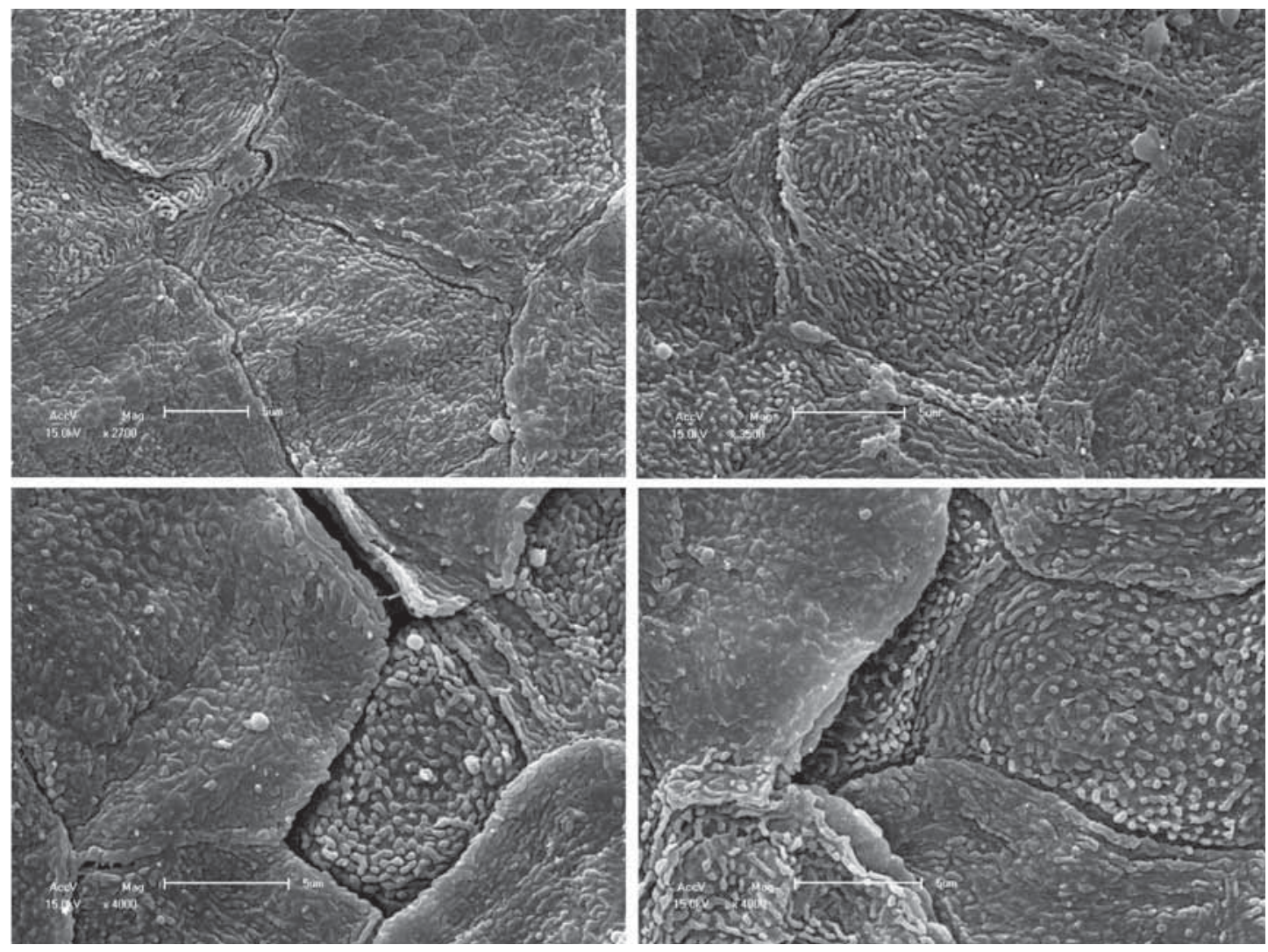

Figure 5: Scanning electron microscopy detail of the lower corneocytes showing irregular cell outline, intercellular clefts and villous projections $(\times 2.700-$ $4.000)$.

and compact keratine. The outer surface showed the keratine without the normal elimination of corneocytes, confirming abnormal keratinization. The inner surface revealed the lower corneocytes, which have a villous membrane, unlike the normal eliminated corneocytes in the outer surface, which have a smooth surface.

These findings are hard to compare, since only

\section{REFERENCES}

1. Hallopeu $H$, Watelet R. Sur une forme atténuée de la maladie dite ichtyose fetale. Ann Dermatol Syphilol 1884;3:149-152.

2. Goldsmith L, Katz S, Gilchrest B, Paller A, Leffel D, Wolff K. Fitzpatrick's Dermatology in Gereral Medicine. 8th Ed. New York: MacGraw Hill; 2012.

3. Tüzün Y, İşcimen A, Pehlivan 0. Collodion Baby. J Turk Acad Dermatol 2008;2 82201r.

4. Dreyfus I, Chouquet C, Ezzedine K, Henner S, Chiavérini C, Maza A, et al. Prevalence of inherited ichthyosis in France: a study using capture-recapture method. Orphanet J Rare Dis. 2014:9:1.

5. Craiglow BG. Ichthyosis in the newborn. Semin Perinatol. 2013;37:26-31.

6. Rodríguez-Pazos L, Ginarte M, Vega A, Toribio J. Autosomal recessive congenital ichthyosis. Actas Dermosifiliogr. 2013;104:270-84

7. Raghunath M, Hennies HC, Ahvazi B, Vogel M, Reis A, Steinert PM, et al. Self-healing collodion baby: a dynamic phenotype explained by a particular transglutaminase-1 mutation. J Invest Dermatol. 2003;120:224-8.

8. Terrinoni A, Serra V, Codispoti A, Talamonti E, Bui L, Palombo R, et al. Nove transglutaminase 1 mutations in patients affected by lamellar ichthyosis. Cell Death Dis. 2012;3:e416. reports referring to transmission electron microscopy (TEM) could be found in the literature review. TEM examines cross-sections and not three-dimensional structures. With TEM, lipid inclusions, abnormal lamellar granules and normal desmossomes were described. ${ }^{9,10}$

These ultrastructural aspects of a self-healing collodion baby need to be compared with further cases and with other forms of collodion baby. $\square$

9. Akiyama M, Shimizu H, Yoneda K, Nishikawa T. Collodion baby: ultrastructure and distribution of cornified cell envelope proteins and keratins. Dermatology. 1997; 195:164-8.

10. Ergezinger K, Hamm H, Erhard H, Kolde G, von Stockhausen HB. "Selbstheilende" Form eines Kollodiumbabys Transiente Verhornungsstörung oder Minimalform einer lamellären Ichthyose? Monatssch Kinderheilkunde. 1998;146:1070-3.

M AILING ADDRESS:

H iram Larangeira de A Imeida JR

Rua Gonçal ves Chaves, 457

96015-560 Pelotas, RS.

E-mail: hiramalmeidaj $@$ @otmail.com

How to cite this article: Almeida Jr HL, Isaacsson H, Guarenti IM, Marques e Silva R, Suita de Castro LA. Scanning electron microscopy of the collodion membrane from a self-healing collodion baby. An Bras Dermatol. 2015;90(4):581-4. 